\title{
DETERMINAN SIKAP RESIDEN TERHADAP NARKOBA DI KLINIK REHABILITASI BADAN NARKOTIKA NASIONAL PROPINSI SULAWESI SELATAN
}

\section{DETERMINANTS OF RESIDENT ATTITUDE TOWARDS DRUGS IN REHAB CLINIC NATIONAL NARCOTICS AGENCY PROVINCE OF SOUTH SULAWESI}

\author{
I Made Sudarta ${ }^{1}$, A. Ummu Salmah', Veni Hadju ${ }^{3}$ \\ ${ }^{1}$ Poltekkes Kemenkes Mamuju \\ ${ }^{2}$ Departemen Kesehatan Reproduksi dan Keluarga, Fakultas Kesehatan Masyarakat, UNHAS \\ ${ }^{3}$ Departemen Ilmu Gizi, Fakultas Kesehatan Masyarakat, UNHAS
}

\begin{abstract}
Alamat Korespondensi : I Made Sudarta, Jl. Perum Depag Blok A1 No. 13 Makassar, 085394003997 Email: sudharta.made@gmail.com
\end{abstract}

\begin{abstract}
ABSTRAK
Hasil survei yang dilakukan oleh Badan Narkotika Nasional dan Pusat Penelitian Kesehatan UI tahun 2008 diperoleh angka prevalensi mencapai 1,9\% dan pada tahun 2011 meningkat hingga 2,2\% atau lebih kurang 4 juta penduduk Indonesia usia 10 sampai dengan 60 tahun sebagai penyalah guna narkotika. Penelitian ini bertujuan untuk menganalisis faktor determinan sikap residen terhadap narkoba di Klinik Rehabilitasi BNNP Sulawesi Selatan Tahun 2017. Penelitian ini merupakan jenis penelitian observasional dengan rancangan Cross Sectional Study. Populasi dalam penelitian ini adalah semua residen yang menjalani rehabilitasi di Klinik Rehabilitasi BNNP Sulawesi Selatan Tahun 2017 sebanyak 119 orang. Sampel pada penelitian ini adalah semua residen yang hadir pada saat dilakukan penelitian dan bersedia serta layak untuk diwawancara sebanyak 65 orang. menggunakan teknik purposive sampling. Data dikumpulkan dengan wawancara menggunakan kuesioner. Data dianalisis secara univariat dengan distribusi frekuensi, bivariat dengan menggunakan uji chi square dan multivariat dengan regresi logistik berganda. Hasil penelitian menunjukkan bahwa proporsi terbesar adalah pada kelompok umur 20-29 Tahun (46,2\%), jenis kelamin laki-laki (86,2\%). berpendidikan rendah $(66,2 \%)$, tinggal bersama orangtua $(41,9 \%)$, pegawai swasta $(36,9 \%)$. Pada analisis bivariat, variabel yang signifikan berhubungan dengan sikap residen yaitu lama rehabilitasi $(p=0,033)$, fungsi keluarga $(p=0,000)$, dukungan keluarga $(p=0,010)$ dan kelompok teman sebaya $(p=0,004)$. Pada analisis multivariat, variabel yang paling berhubungan dengan sikap residen yaitu fungsi keluarga $(\mathrm{p}=0,002)$. Disimpulkan bahwa terdapat hubungan lama rehabilitasi, fungsi keluarga, dukungan keluarga dan kelompok teman sebaya dengan sikap residen terhadap narkoba.
\end{abstract}

Kata kunci: Sikap, residen, narkoba.

\begin{abstract}
$A B S T R A C T$
The results of a survey conducted by the National Narcotics Agency and Health Research Center UI year 2008 retrieved prevalence reached $1.9 \%$ and in 2011 rose to $2.2 \%$ or approximately 4 million inhabitants of Indonesia ages 10 up to 60 years as to misuse narcotics. This research aims to analyze the determinants of resident's attitude towards drugs in rehab clinic BNNP of South Sulawesi, the year 2017. This research is a type of observational research with Cross Sectional Study. The population in this study are all resident who underwent rehabilitation BNNP Rehabilitation Clinic in South Sulawesi, the year 2017 as much as 119 people. The samples in this research are all resident present at the time of research and are willing to do and deserves to be interviewed as many as 65 people. Using a purposive sampling technique. The data are collected with interviews using questionnaire. The data analyzed in univariate frequency distributions, bivariat with using test chi square and multivariate logistic regression with multiple. The results showed that the biggest proportion was in the age group of 20 - 29 years $(46.2 \%)$, the male gender $(86.2 \%)$. the low educated (66.2\%), living with parents $(41.9 \%)$, employees of the private sector (36.9\%). On the bivariat analysis, the significant variables associated with the attitude of residents that are long rehabilitation $(p=0.033)$, family function $(p=0.000)$, family support $(p=0.010)$ and peer group $(p=0.004)$. On Multivariate analysis, the variables that are most related to attitude of the resident family functions namely $(p=0.002)$. It was concluded that there is a relationship of long rehabilitation, family functions, family support and peer group with resident's attitude towards drugs.
\end{abstract}

Keywords:attitude, resident, drugs. 


\section{PENDAHULUAN}

United Nations Office on Drugs and Crime (UNODC) mencatat adanya peningkatan tajam baik dari segi produksi, peredaran gelap, maupun penyalahgunaan narkoba. Kondisi lebih memprihatinkan karena faktanya, mayoritas korban penyalahguna narkoba adalah generasi muda dengan kelompok usia produktif dan hal itu terjadi di seluruh dunia (BNN,2011).

Korban penyalahgunaan narkotika di Indonesia akhir-akhir ini cenderung meningkat dan mencakup tidak hanya terbatas pada kelompok masyarakat yang mampu tetapi juga telah merambah kelompok masyarakat yang kurang mampu baik di kota maupun di desa. Tidak hanya melibatkan pelajar/ mahasiswa namun telah merambah pelajar setingkat SMP dan SD. Penggunaan pertama narkoba terjadi karena penawaran, bujukan, atau tekanan seseorang atau sekelompok orang misalnya teman sebaya. Didorong rasa ingin tahu, ingin mencoba, atau ingin memakai, individu mau menerima tawaran itu (Trisakti,2014).

Penyalahgunaan narkotika dan bahan adiktif (Narkoba) di Indonesia merupakan masalah yang sangat mengkhawatirkan. Terutama pada remajaremaja saat ini yang makin dekat dengan narkoba. Karena posisi Indonesia sekarang ini tidak hanya sebagai daerah transit maupun pemasaran narkotika, psikotropika dan zat adiktif, melainkan sudah menjadi daerah produsen narkotika, psikotropika dan zat adiktif (BNN,2011).

World Drug Report (2012) menyatakan bahwa pada tahun 2010 terdapat sekitar 230 juta orang atau sekitar 5\% penduduk dunia usia 15-64 tahun yang menyalahgunakan obat setidaknya satu kali dalam 12 bulan. Dari semua jenis penyalahgunaan obat, ganja merupakan zat yang paling banyak digunakan yaitu antara 119 juta sampai 224 juta. Hasil survei yang dilakukan oleh BNN (Badan Narkotika Nasional) dan Puslitkes (Pusat Penelitian Kesehatan) UI tahun 2008 diperoleh angka prevalensi mencapai $1,9 \%$ dan pada tahun 2011 meningkat hingga 2,2\% atau lebih kurang 4 juta penduduk Indonesia usia 10 sampai dengan 60 tahun sebagai penyalah guna narkotika (BNN,2011).

Layanan rehabilitasi melalui BNN Wilayah Sulawesi Selatan tahun 2016 mencatat sebanyak 1.187 orang yang terdiri dari 702 orang rawat inap (RI) dan 515 orang rawat jalan (RJ). Klien tersebut terdistribusi berdasarkan jenis layanan pada Lembaga Institusi Pemerintah, (BNNP Sul-Sel,2016).

Hasil penelitian yang dilakukan oleh Jalilian (2015) menunjukkan bahwa sikap $(\mathrm{OR}=1,062)$ adalah prediktor yang paling berpengaruh terhadap penyalahgunaan narkoba. Terdapat hubungan positif antara risk factors dengan sikap terhadap penggunaan napza. Artinya, semakin tinggi risk factors maka semakin positif sikap terhadap penggunaan napza yang dimiliki oleh subjek. Sebaliknya, semakin rendah risk factors maka semakin negatif sikap terhadap penggunaan napza yang dimiliki oleh subjek (Suyasa,2006). Penelitia ini bertujuan untuk menganalisis determinan sikap residen terhadap narkoba di Klinik Rehabilitasi BNNP Sulawesi Selatan Tahun 2017.

\section{METODE PENELITIAN}

\section{Lokasi dan Jenis Penelitian}

Penelitian ini dilaksanakan di Klinik Rehabilitasi BNNP Sulawesi Selatan. Menggunakan desain "Studi potong lintang" (Cross Sectional Study) yang merupakan salah satu jenis rancangan penelitian yang sifatnya analitik dan termasuk dalam jenis 
rancangan penelitian observasional. Metode yang digunakan dalam penelitian ini adalah metode survey, yaitu metode pengumpulan data dengan mengambil sampel dari populasi dan wawancara dengan menggunakan kuesioner sebagai instrumen pengumpulan data.

\section{Populasi dan sampel}

Populasi dalam penelitian ini adalah semua residen yang menjalani rehabilitasi di Klinik Rehabilitasi BNNP Sulawesi Selatan. Sampel pada penelitian ini adalah semua residen yang hadir pada saat dilakukan penelitian dan bersedia serta layak untuk diwawancara sebanyak 65 responden. menggunakan teknik exhaustive sampling.

\section{Pengumpulan data}

Pengumpulan data dalam penelitian ini dilakukan dengan menggunakan alat bantu kuesioner.

\section{Analisis data}

Data dianalisis dengan menggunakan program SPSS dengan distribusi frekuensi, uji chi square dan regresi logistik berganda.

\section{HASIL PENELITIAN}

Tabel 1 menunjukkan bahwa sebagian besar responden berumur 20-29 Tahun $(46,2 \%)$, berjenis kelamin laki-laki $(86,2 \%)$, berpendidikan rendah $(66,2 \%)$, suku Makassar (49,2\%). Beragama Islam (96,9\%), tinggal bersama orang tua $(41,5 \%)$, bekerja sebagai karyawan swasta (36,9\%), menggunakan stimulansia $(73,8 \%)$, menjalani rehabilitasi $\leq 3$ bulan $(61,5 \%)$, fungsi keluarga efektif $(70,8 \%)$, dukungan keluarga $(64,6 \%)$ mendukung, tidak berteman dengan kelompok teman sebaya $((58,5 \%)$, sikap negatif $(66,2 \%)$.

Tabel 2 hasil analisis bivariat menunjukkan bahwa responden memiliki sikap negatif dengan narkoba jenis depresansia $(12,3 \%)$ sedangkan stimulansia $(53,8 \%)$ dan $p>\alpha \quad(0,05)$, responden yang memiliki sikap negatif dengan lama rehabilitasi $>3$ bulan $(32,3 \%)$ sedangkan $\leq$ bulan $(33,8 \%)$ dan $\mathrm{p}<\alpha(0,05)$, responden yang memiliki sikap negatif dengan fungsi keluarga efektif $(56,9 \%)$ sedangkan fungsi keluarga tidak efektif $(9,2 \%)$ dan $p<\alpha$ $(0,05)$, responden yang memiliki sikap negatif dengan dukungan keluarga mendukung $(50,8 \%)$ sedangkan tidak mendukung $(15,4 \%)$ dan $p<\alpha \quad(0,05)$, responden yang memiliki sikap negatif berteman dengan kelompok teman sebaya $(18,5 \%)$ sedangkan tidak berteman $(47,7 \%)$ dan $p<\alpha(0,05)$. Tabel 3 memaparkan hasil analisis multivariat menunjukkan bahwa hasil uji statistik dengan regresi logistik berganda diperoleh variabel yang secara simultan berhubungan dengan sikap residen terhadap narkoba yaitu lama rehabilitasi $\mathrm{p}=0,014$ dan fungsi keluarga $\mathrm{p}=0,002$.

Tabel 1. Karakteristik Responden

\begin{tabular}{|c|c|c|c|}
\hline Variabel & Kriteria & Frekuensi & Persentase \\
\hline Umur (Tahun) & $\begin{array}{l}<20 \\
20-29 \\
30-39 \\
40-49\end{array}$ & $\begin{array}{c}9 \\
30 \\
23 \\
3\end{array}$ & $\begin{array}{c}13,8 \\
46,2 \\
35,4 \\
4,6\end{array}$ \\
\hline Jenis kelamin & $\begin{array}{l}\text { Laki - laki } \\
\text { Perempuan }\end{array}$ & $\begin{array}{c}56 \\
9\end{array}$ & $\begin{array}{l}86,2 \\
13,8\end{array}$ \\
\hline Pendidikan & Rendah (SD-SMA) & 43 & 66,2 \\
\hline Suku & $\begin{array}{l}\text { Tinggi }(>D \text { 3) } \\
\text { Makassar } \\
\text { Bugis } \\
\text { Lainnya }\end{array}$ & $\begin{array}{c}22 \\
32 \\
30 \\
3\end{array}$ & $\begin{array}{l}33,8 \\
49,2 \\
46,2 \\
4,6\end{array}$ \\
\hline Agama & $\begin{array}{l}\text { Islam } \\
\text { Kristen khatolik } \\
\text { Budha }\end{array}$ & $\begin{array}{c}63 \\
1 \\
1\end{array}$ & $\begin{array}{c}96,9 \\
1,5 \\
1,5\end{array}$ \\
\hline $\begin{array}{l}\text { Status tempat } \\
\text { Tinggal }\end{array}$ & $\begin{array}{l}\text { Bersama orang tua } \\
\text { Kos } \\
\text { Bersama saudara/teman } \\
\text { Lainnya }\end{array}$ & $\begin{array}{c}27 \\
20 \\
5 \\
13\end{array}$ & $\begin{array}{c}41,5 \\
30,8 \\
7,7 \\
20,0\end{array}$ \\
\hline Pekerjaan & $\begin{array}{l}\text { PNS/TNI/POLRI } \\
\text { Pelajar/Mahasiswa } \\
\text { Pegawai swasta } \\
\text { Tidak bekerja } \\
\text { Wiraswasta } \\
\text { Lainnya }\end{array}$ & $\begin{array}{c}1 \\
15 \\
24 \\
4 \\
19 \\
2\end{array}$ & $\begin{array}{c}1,5 \\
23,1 \\
36,9 \\
6,2 \\
29,2 \\
3,1\end{array}$ \\
\hline $\begin{array}{l}\text { Lama } \\
\text { Mengkonsumsi }\end{array}$ & $(1-6)$ bulan & 64 & 98,5 \\
\hline $\begin{array}{l}\text { narkoba } \\
\text { Jenis narkoba }\end{array}$ & $\begin{array}{l}>2 \text { tahun } \\
\text { Depresansia } \\
\text { Stimulansia }\end{array}$ & $\begin{array}{c}1 \\
17 \\
48\end{array}$ & $\begin{array}{c}1,5 \\
26,2 \\
73,8\end{array}$ \\
\hline Lama Rehabilitasí & $\begin{array}{l}>3 \text { bulan } \\
\leq 3 \text { bulan }\end{array}$ & $\begin{array}{l}25 \\
40\end{array}$ & $\begin{array}{l}38,5 \\
61,5\end{array}$ \\
\hline Fungsi keluarga & $\begin{array}{l}\text { Efektif } \\
\text { Tidak efektif }\end{array}$ & $\begin{array}{l}46 \\
19\end{array}$ & $\begin{array}{l}70,8 \\
29,2\end{array}$ \\
\hline $\begin{array}{l}\text { Dukungan } \\
\text { Keluarga }\end{array}$ & $\begin{array}{l}\text { Mendukung } \\
\text { Tidak mendukung }\end{array}$ & $\begin{array}{l}42 \\
23\end{array}$ & $\begin{array}{l}64,6 \\
35,4\end{array}$ \\
\hline $\begin{array}{l}\text { Kelompok Teman } \\
\text { Sebava }\end{array}$ & $\begin{array}{l}\text { Berteman } \\
\text { Tidak berteman }\end{array}$ & $\begin{array}{l}27 \\
38\end{array}$ & $\begin{array}{l}41,5 \\
58,5\end{array}$ \\
\hline Sikap & $\begin{array}{l}\text { Negatif } \\
\text { Positif }\end{array}$ & $\begin{array}{l}43 \\
22 \\
\end{array}$ & $\begin{array}{l}66,2 \\
33,8 \\
\end{array}$ \\
\hline Total & & 65 & 100 \\
\hline
\end{tabular}

Sumber: Data Primer 2017. 
Tabel 2. Hasil Analisis Detreminan Sikap Residen Terhadap Narkoba

\begin{tabular}{|c|c|c|c|c|c|c|c|}
\hline \multirow{3}{*}{ Variabel Penelitian } & \multicolumn{4}{|c|}{ Sikap Terhadap Narkoba } & & & \multirow{3}{*}{$\mathbf{p}$} \\
\hline & \multicolumn{2}{|c|}{ Negatif } & \multicolumn{2}{|c|}{ Positif } & \multicolumn{2}{|c|}{ Total } & \\
\hline & $\mathbf{n}$ & $\%$ & $\mathbf{n}$ & $\%$ & $\mathbf{n}$ & $\%$ & \\
\hline \multicolumn{8}{|l|}{ Jenis Narkoba } \\
\hline Depresansia & 8 & 12,3 & 9 & 13,8 & 17 & 26,2 & 0,101 \\
\hline Stimulansia & 35 & 53,8 & 13 & 20,0 & 48 & 73,8 & \\
\hline \multicolumn{8}{|l|}{ Lama Rehabilitasi } \\
\hline$>3$ Bulan & 21 & 32,3 & 4 & 6,2 & 25 & 38,5 & 0,033 \\
\hline$\leq$ Bulan & 22 & 33,8 & 18 & 27,7 & 40 & 61,5 & \\
\hline \multicolumn{8}{|l|}{ Fungsi Keluarga } \\
\hline Efektif & 37 & 56,9 & 9 & 13,8 & 46 & 70,8 & 0,000 \\
\hline Tidak Efektif & 6 & 9,2 & 13 & 20,0 & 19 & 29,2 & \\
\hline \multicolumn{8}{|l|}{ Dukungan keluarga } \\
\hline Mendukung & 33 & 50,8 & 9 & 13,8 & 42 & 64,6 & 0,010 \\
\hline Tidak Mendukung & 10 & 15,4 & 13 & 20,0 & 23 & 35,4 & \\
\hline \multicolumn{8}{|l|}{$\begin{array}{l}\text { Kelompok Teman } \\
\text { Sebaya }\end{array}$} \\
\hline Berteman & 12 & 18,5 & 15 & 23,1 & 27 & 41,6 & 0,004 \\
\hline Tidak Berteman & 31 & 47,7 & 7 & 10,8 & 38 & 58,4 & \\
\hline
\end{tabular}

Sumber: Data Primer, 2017

Tabel 3. Hasil Analisis Regresi Linear Berganda dari Sikap Residen Terhadap Narkoba

\begin{tabular}{lllll}
\hline \multicolumn{1}{c}{ Variabel } & B & Wald & p \\
\hline \multirow{2}{*}{ Step 1 } & Jenis Narkoba & $-1,226$ & 1,931 & 0,165 \\
& Lama Rehabilitasi & 2,371 & 6,719 & 0,010 \\
& Fungsi Keluarga & 1,865 & 5,458 & 0,019 \\
& Dukungan Keluarga & 0,972 & 1,744 & 0,187 \\
& Kelompok Teman Sebaya & $-0,950$ & 1,626 & 0,202 \\
\hline \multirow{2}{*}{ Step 2 } & Jenis Narkoba & $-1,209$ & 2,028 & 0,154 \\
& Lama Rehabilitasi & 2,384 & 6,793 & 0,009 \\
& Fungsi Keluarga & 2,147 & 7,852 & 0,005 \\
& Dukungan Keluarga & 1,276 & 3,436 & 0,064 \\
\hline Step 3 & Lama Rehabilitasi & 1,990 & 5,997 & 0,014 \\
& Fungsi Keluarga & 2,298 & 9,441 & 0,002 \\
& Dukungan Keluarga & 1,310 & 3,790 & 0,052 \\
\hline
\end{tabular}

Sumber: Data Primer, 2017 


\section{PEMBAHASAN}

Hasil penelitian yang dilakukan di Klinik Rehabilitasi BNNP Sulawesi Selatan Jalan Manunggal 22 Kel. Maccini Sombala Kec. Tamalate, Makassar menunjukkan bahwa sebagian besar residen memiliki sikap negatif terhadap narkoba $(66,2 \%)$. Sikap negatif ini tidak lepas dari proses rehabilitasi yang dijalani oleh residen. Apabila sikap terhadap penggunaan narkoba positif maka remaja mempunyai kecenderungan menggunakan narkoba. Hal ini misalnya dikarenakan keyakinan bahwa penggunaan narkoba tidak membahayakan jiwanya dan lagi pula membuatnya berani berbicara sehingga lebih percaya diri. Sebaliknya, apabila remaja misalnya yakin bahwa penggunaan narkoba memiliki resiko tinggi maka sikapnya terhadap penggunaan narkoba akan melemah dan cenderung bersifat negatif terhadap penggunaan narkoba. Terdapat hubungan positif antara risk factors dengan sikap terhadap penggunaan napza. Artinya, semakin tinggi risk factors maka semakin positif sikap terhadap penggunaan napza yang dimiliki oleh subjek.

Hasil penelitian analisis uji ChiSquare didapatkan hasil nilai $p>\alpha(0,05)$ yang menunjukkan tidak terdapat hubungan yang bermakna antara jenis narkoba dengan sikap residen terhadap narkoba di klinik rehabilitasi BNNP Sulawesi Selatan. Berdasarkan hasil penelitian menunjukan mayoritas responden mengkonsumsi narkoba jenis stimulan $(73,8 \%)$. Stimulan adalah zat yang merangsang sistim saraf pusat sehingga mempercepat proses proses dalam tubuh, seperti meningkatnya detak jantung, pernapasan dan tekanan darah. Stimulan dapat membuat orang lebih siaga dan menyembunyikan kelelahan. Stimulan menaikkan kegiatan sistem saraf simpatetik, sistem saraf pusat (CNS) atau keduanya sekaligus. Beberapa stimulan meghasilkan sensasi kegirangan yang berlebihan, Pemakaian zat ini biasanya karena mengharapkan efek euphoria, menimbulkan rasa percaya diri, memperbaiki penampilan, mengurangi rasa lelah, mengurangi rasa ngantuk dan rasa lapar. Karena alasan itulah zat stimulan banyak disalahgunakan. Pengguna Depresan memakainya karena menginginkan efek; relaksasi, menurunnya anxietas (kecemasan), menurunnya hambatan, rasa sejahtera dan euphoria sedang. Efek samping dari penggunan zat ini; konsentrasi buruk, kelemahan otot, koordinasi kurang, bicara cadel, pening, reflex lambat, suka mual dan muntah, gangguan penilaian, kebingungan mental, hilang ingatan dan emosi tumpul.

Hasil penelitian analisis uji ChiSquare didapatkan hasil nilai $\mathrm{p}<\alpha(0,05)$ yang menunjukkan terdapat hubungan yang bermakna antara Lama Rehabilitasi dengan sikap residen terhadap narkoba. Hal ini berarti bahwa semakin lama residen menjalani proses rehabilitasi sikap akan semakin negatif terhadap narkoba. Sikap negatif terhadap narkoba cenderung akan menjauhi narkoba tersebut. Dalam perjalanan menuju kesembuhan dari kecanduan narkoba, tak jarang individu harus menjalani beberapa kali rehabilitasi karena mereke kembali menggunakan narkoba setelah berhenti untuk beberapa waktu. Namun, tak sedikit juga dari beberpa pecandu narkoba yang berhasil untuk berhenti dari penggunaan narkoba setelah menjalani satu kali rehabilitasi. Rehabilitasi memberikan peran terpenting dalam pembinaan bagi pecandu narkoba. Sesuai dengan Pasal 35 ayat 2 tahun 2009 tentang narkotika dijelaskan bahwa, rehabilitasi adalah proses kegiatan penyembuhan secara terpadu terhadap fisik, mental dan sosial untuk membebaskan para pecandu dari ketergantungan narkotika. Proses penyembuhan ini tentunya dibimbing secara terpadu oleh sebuah lembaga, baik secara mandiri maupun merupakan bimbingan dari pemerintah.

Hasil penelitian analisis uji ChiSquare didapatkan hasil nilai $\mathrm{p}<\alpha(0,05)$ yang menunjukkan terdapat hubungan yang bermakna antara fungsi keluarga dengan sikap residen terhadap narkoba. Ini 
berarti bahwa fungsi keluarga yang efektif memberikan pengaruh terhadap sikap yang negatif terhadap narkoba dan fungsi keluarga yang tidak efektif memberikan pengaruh terhadap sikap yang positif terhadap narkoba. Sikap yang positif terhadap narkoba berdampak terhadap risiko relaps atau kembali menggunakan narkoba. Friedman dalam Setyowati (2008), lima fungsi dasar keluarga salah satunya adalah fungsi perawatan kesehatan yaitu kemampuan keluarga dalam merawat anggota keluarga yang mengalami masalah kesehatan. Jadi keluarga yang mempunyai anggota penyalahguna narkoba harus mampu mengatasi masalah kesehatan dengan cara keluarga mendukung penyalahguna untuk melakukan pemulihan di panti rehabilitasi narkoba baik rehabilitasi medis ataupun rehabilitasi sosial. Faktor keluarga dalam hubungannya dengan penyalahguna narkoba memiliki keterkaitan yang sangat erat sebagai bagian dari fungsi dalam keluarga.

Hasil penelitian analisis uji ChiSquare didapatkan hasil nilai $\mathrm{p}<\alpha(0,05)$ yang menunjukkan terdapat hubungan yang bermakna antara dukungan keluarga dengan sikap residen terhadap narkoba, dimana keluarga yang mendukung terhadap proses rehabilitasi berpengaruh terhadap sikap yang negatif terhadap narkoba dan residen yang tidak memperoleh dukungan oleh keluarga berpengaruh terhadap sikap yang positif terhadap narkoba. Hal ini tentunya akan menghambat proses kesembuhan residen untuk bisa berhenti atau sembuh dari narkoba. Hasil penelitian yang dilakukan oleh Pranatha (2016) menunjukan bahwa terdapat hubungan yang positif antara dukungan keluarga dengan kejadian kekambuhan pada penyalahguna narkoba di rumah damping Tenjo Laut Kabupaten Kuningan Tahun 2016 dengan nilai $\mathrm{p}=$ 0,026. Hal ini dapat diartikan bahwa semakin baik dukungan keluarga terhadap penyalahguna narkoba dalam upaya pemulihan maka semakin kecil risiko penyalahguna narkoba mengalami kekambuhan.

Hasil penelitian analisis uji ChiSquare didapatkan hasil nilai $\mathrm{p}<\alpha(0,05)$ yang menunjukkan terdapat hubungan yang bermakna antara kelompok teman sebaya dengan sikap residen terhadap narkoba. Dimana residen yang cenderung menghabiskan waktunya lebih banyak dengan teman dibandingkan dengan keluarga meiliki sikap yang positif terhadap narkoba. Hasil penelitian ini sejalan dengan penelitian Kurnia (2013) mengungkapkan bahwa teman sebaya merupakan faktor sosial yang menjadikan seorang penyalahguna NAPZA mengalami kekambuhan (relaps). Kelompok teman sebaya mempunyai potensi yang besar sebagai lingkungan untuk berubah. Kelompok teman sebaya dapat menjadi media awal bagi remaja dalam mengenal dan mencoba NAPZA. Terjadi dilema dalam diri remaja di satu sisi menyadari bahaya dan penerimaan dan pengakuan kelompok. Dukungan kelompok dan proses seleksi kelompok sangat berarti terutama bagi remaja yang sangat tergantung secara emosional pada kelompoknya sehingga semua aturan yang berlaku dalam kelompok sangat di patuhi.

\section{KESIMPULAN DAN SARAN}

Berdasarkan hasil penelitian dapat disimpulkan bahwa ada hubungan antara lama rehabilitasi, fungsi keluarga, dukungan keluarga, dan kelompok teman sebaya dengan sikap residen terhadap narkoba. Berdasarkan analisis regresi logistik faktor yang paling berhubungan dengan sikap residen terhadap narkoba adalah lama rehabilitasi dan fungsi keluarga. Sehingga disarankan klinik rehabilitasi mendesain program pendampingan (family therapy) terhadap orang tua atau keluarga, tidak hanya berupa pemantauan tetapi juga pengetahuan mengenai mencegah terjadinya relaps. Pendampingan keluarga yang tak pernah putus dapat membantu pecandu narkoba untuk benar-benar berhenti menggunakan obat-obatan terlarang itu. Dalam rehabilitasi, keluarga 
pun ikut mendapat terapi.

\section{DAFTAR PUSTAKA}

Anggreni,D.(2015). Dampak Bagi Pengguna Narkotika, Psikotropika Dan Zat Adiktif (Napza) Di Kelurahan Gunung Kelua Samarinda Ulu. eJournal SosiatriSosiologi 2015, 3 (3): 37 - 51 ISSN 0000-0000, ejournal.sos.fisipunmul.ac.id

Asmoro.(2016). Pengaruh Lingkungan Keluarga terhadap Penyalahgunaan NAPZA pada Remaja BNN Kota Surabaya Tahun 2016. Jurnal Biometrika dan Kependudukan, Vol. 5, No. 1 Juli 2016: 80-87.

Azwar, S.(2012). Sikap Manusia Teori dan Pengukurannya Edisi Ke 2. Pustaka Pelajar. Yogyakarta.

Cianfrone \& Pentangelo.(2011). Phamacological Drugs Inducing Ototoxicity, Vestibular Symptoms and Tinnitus: A Reasoned and Updated Guide. European Review for Medical and Pharmacological Sciences; 2011;15: 601-636, 15

Cheung, C. K. \& Tse, J. W. (2010). Popularity Among Peers As A Condition For A Child's Risk of Substance Abuse. Journal of Drug Issues; Summer 2010; 40, 3, 577.

Friedman, M.M. (2010). Keperawatan Keluarga Teori dan Praktik. EGC. Jakarta.

Golestan, S. 2010. The Role of Family Factors on the Relapse Behavior of Male Adolescent Opiate Abusers in Kerman (A Province in Iran). Malaysia: Journal Asian Culture and History Vol. 2 No. 1, 2.

Hawari, D.(2012). Penyalahgunaan \& Ketergantungan Naza Edisi Kedua.Badan Penerbit FKUI.jakarta.

Jalilian,F.et all.2015. Cognitive Factors Related to Drug Abuse Among a Sample of Iranian Male Medical College Students. Global Journal of Health Science; Vol. 7, No. 5; 2015
Kholik. S.et all. 2014. Faktor-Faktor Yang Mempengaruhi Penyalahgunaan Narkoba Pada Klien Rehabilitasi Narkoba Di Poli Napza Rsj Sambang Lihum. Jurnal Skala Kesehatan Volume 5 No. 1.

Kurnia.(2015). Faktor Kekambuhan Pada Pengguna Napza Di Rs. Khusus Jiwa Soeprapto Bengkulu. Mitra Raflesia Vol. 7 No. 2 JuliDesember.2015

Nurhidayati,N, dkk.(2014). Hubungan antara Dukungan Sosial Keluarga dengan Self Esteem pada Penyalahguna Narkoba yang Direhabilitasi. Jurnal Psikologi Klinis dan Kesehatan Mental Vol. 03 No. 03, Desember 2014.

Pranatha. 2017. Hubungan Antara Dukungan Keluarga Dengan Kejadian Kekambuhan (Relaps) Pada Penyalahguna Narkobadi Rumah Damping Tenjo Lautkabupaten Kuningan Tahun 2016. Jurnal Skolastik Keperawatan.Vol.3, No. 1 Jan Jun 2017. Issn: 2443 - 0935 EIssn: $2443-1699$

Rowe, C. L. (2012). Family Therapy For Drug Abuse: Review and Updates 2003-2010. Miami: Journal Of Marital And Family Therapy; January 2012, Volume 38, No. 1,59-81, 38.

Saad,B.M,et all.(2016). Drug and Substance Abuse among Youth: A rehabilitation centre in Kuala Lumpur . 2nd AQoL2015Izmir, Turkey, 09-14 Dec. 2015 / E-BPJ, 1(2) July 2016 (Pp. 3-11)

Schafer.G.(2011). Family Functioning In Families With Alcohol And Other Drug Addiction. June 2011.Issue 37. Social Policy Journal of New Zealand

Scull, T. M.(2010). Adolescents' Mediarelated Cognitions and Substance Use in the Context of Parental and Peer Influences. J Youth Adolesc 39(9): 981-998, 39. 